\title{
Procedure Link Identifier
}

National Cancer Institute

\section{Source}

National Cancer Institute. Procedure Link Identifier. NCI Thesaurus. Code C117509.

A sequence of characters used as a linkage between related procedure records. 